\section{Vladimir Prelog (1906-98)}

\section{Pioneer of stereochemistry}

Until quite recently, the nonagenarian Vladimir Prelog was a familiar figure in the chemistry building of the ETH. Conspicuous in his immaculate, white laboratory coat, he could be seen in the corridors or in the Chemiebar, where he drank his coffee most mornings and afternoons. New students used to ask: "Who is that elderly gentleman in the white lab coat? Is he a laboratory technician?" On being told that this was Prelog, the Nobel prizewinner, they were impressed, for they knew his name from the first-year lectures. We shall see him no more. Vladimir Prelog, one of the great organic chemists of our century, died on 7 January after a short illness. He is survived by his wife and son.

A child of the old Austro-Hungarian empire, Prelog was born in Sarajevo on 23 July 1906 . He was present at the fateful visit of the Austrian crown prince, Archduke Franz Ferdinand, on 28 June 1914, when, waiting to throw flowers in front of the state carriage, he heard the shots that presaged the end of that era. His school years were passed in Zagreb, after which he studied chemistry at the Prague Institute of Technology, obtaining his doctorate in 1929 with Emil Votoček but being influenced more by Rudolf Lukeš, who led him into the chemical world of alkaloids. It was the time of the great depression, and Prelog supported himself 'semi-legally' by preparing chemicals in a commercial laboratory whose owner and director became Prelog's first doctoral student. In 1935 he moved back to Zagreb, where he taught at the university, first as lecturer and then as professor. Meanwhile, he was associated with a fledgling chemical company in Zagreb (which later developed into Pliva, the largest Yugoslav pharmaceutical company). His commercial preparation of sulphanilamide (Streptazol) brought the financial support needed for his research.

In 1941, after the German occupation of Yugoslavia, he managed to escape under adventurous circumstances to Zürich in neutral Switzerland. There, at the organic chemistry laboratory of the Federal Institute of Technology (ETH) under his fellow countryman Leopold Ruzicka, he found a temporary refuge, which gradually developed into a home in every sense of the word. If the ETH gave Prelog a home, Prelog brought fame to the ETH, with which he was associated for more than $\mathbf{5 0}$ years. After Ruzicka's retirement in 1957,

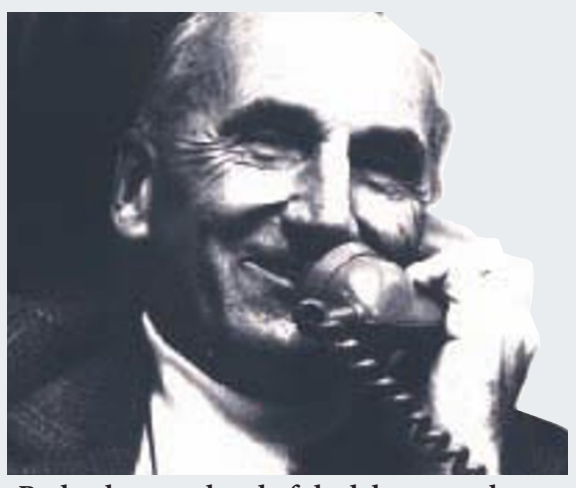

Prelog became head of the laboratory but soon decided to share his powers, and his responsibilities, with his younger colleagues - this was then in continental Europe a mildly revolutionary step for the director of a chemistry institute. After his retirement in 1976 Prelog promptly registered as a special student (Fachhörer) in order to continue his scientific work. At the ETH this is not regarded as an automatic perquisite of a retired professor; it is a privilege for which one may be grateful. Prelog's 1991 autobiographical sketch was entitled, "My 132 Semesters of Chemistry Studies". Renowned as teacher and researcher, he regarded himself as a student to the end.

As an organic chemist, Prelog bridged the gap between the classical tradition and the modern school. When he began his long research career, molecular structure was still being inferred by classical methods, that is to say, by subtle but indirect arguments from chemical reactivity. Success in this area required profound knowledge of chemistry, rigorous logic and, sometimes, a flight of inspiration as well. By mid-century, physical methods - molecular spectroscopy, X-ray analysis and, later, nuclear magnetic resonance - were beginning to displace the traditional chemical methods. Prelog's early work on the structure of alkaloids from Cinchona, Strychnos and other sources was done by classical methods, whereas his later studies of metabolic products of microorganisms were largely based on the newer physical methods. It was mainly through his influence that organic chemistry at the ETH was swift to take advantage of the new techniques.

For his contributions to stereochemistry, Prelog shared the 1975 Nobel prize in chemistry with J. W. Cornforth. Stereochemistry is not so much a branch of chemistry as a way of looking at the science, an explicit concern with molecular shape. Prelog was always fascinated by the spatial forms of organic molecules. One of his early feats in Zagreb was the synthesis of adamantane, with its highly symmetrical molecular structure. Later, in Zürich, he was one of the first to see the importance of steric effects on the reactivity of molecules with medium and large ring systems - for example, the nonreactivity of cyclodecanone towards hydrogen cyanide compared with the ready formation of cyanhydrins of smaller and larger rings. This led him to conformational analysis, and indeed, together with D. H. R. Barton, he was one of the founders of this important branch of modern chemistry. A feature of his later work was the emphasis on steric bulk as a factor in controlling the course of asymmetric synthesis and as a basis for understanding stereospecific reactions in general.

In the mid-1950s, these interests led Prelog to develop, together with his British colleagues R. S. Cahn (then editor of The Chemical Society) and C. K. Ingold, the now universally adopted 'CIP' system of rules for specifying the sense of chirality at tetrahedral stereogenic centres. Towards the end of his life, Prelog was preoccupied with the complexities inherent in this system. There can be few organic chemists of his generation who have had the intellectual strength to master the more mathematical, graph-theoretical aspects of the models they use to describe molecular structures and their interconversions.

Not only as a chemist but also as a person, Prelog made a powerful impression on others. He was admired as a scientist and loved as a person by a multitude of friends from all over the world. A formidable lecturer and talker in general, renowned for his inexhaustible supply of jokes, Yugoslavian folk-sayings, and anecdotes about every famous chemist who has ever lived, he captivated all. Ambitious as far as science was concerned, he was uninterested in the exercise of power - he said that he disliked making decisions that affected other people. $\mathrm{He}$ was seldom provoked to anger and claimed to have an unusually low adrenaline level. But, of course, behind this outward appearance there was a serious, introspective side. His ironic and often self-deprecatory humour was frequently a protective wall for his inner self. Sadly, his last years were clouded by the tragic course of events in his native land, which caused him immeasurable grief and sadness.

\section{Jack D. Dunitz}

Jack D. Dunitz is in the Organic Chemistry Laboratory, Swiss Federal Institute of Technology, ETH-Zentrum, CH-8092, Zürich, Switzerland. e-mail:dunitz@org.chem.ethz.ch 